SOCIAL RESEARCH REPORTS

ISSN: 2066-6861 (print), ISSN: 2067-5941 (electronic)

\title{
ETHICS AND NURSING IN A WIRED WORLD
}

Becky TSARFATI, Daniela COJOCARU

Social Research Reports, 2020, Vol. 12, Issue 2, pp. 17-26

The online version of this article can be found at:

www. researchreports.ro

\section{https://doi.org/10.33788/srr12.2.2}

Published by:

Expert Projects Publishing House

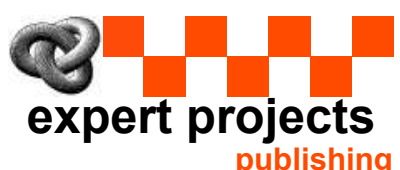

Covered by Index Copernicus International

www.indexcopernicus.com

Directory of Open Access Journals

www.doaj.org

On behalf of:

Center for Program and Social Development

Aditional services and information about Social Research Reports can be found at:

www.researchreports.ro 


\title{
ETHICS AND NURSING IN A WIRED WORLD
}

\author{
Becky TSARFATI ${ }^{1}$, Daniela COJOCARU ${ }^{2}$
}

\begin{abstract}
In recent years, healthcare givers and patients have extensively used computerized technologies and digital information. This changed the work environment and skills of nurses who learn to live with innovations, namely working with both "machines" and humans. Nursing is patient-centered, respecting human dignity and acknowledging patients' needs. Nurses are required to promote safe environment and health care, educate, and embrace a health policy for individuals of all ages and communities. Electronic health records are shared through network systems not only by patients but also by physicians, nurses, insurance personnel, government officials and more. This widespread access to health information requires finding ways for observing patients' confidentiality and privacy by the users. This paper presents four central ethical issues stemming from the use of electronic records: the built-in conflict between nurses' quality care commitment to health system organization and their commitment to maintain patients' respect and privacy; the gap between the one-dimensional reporting of medical and therapeutic information through technological systems; the gap between the advantage of technological systems as being easy to operate and use and the risk of leaking confidential medical information, violating patients' privacy. 4) Conflict between nurses' classic professional identity as people who take care of and satisfy patients' needs and the new concept of nursing that advocates patients' privacy, autonomy and dignity while learning new technological skills with all the advantages and disadvantages encompassed in it. This paper ends with a writes' point of view about ethical-technological solutions of the ethical issues.
\end{abstract}

Keywords: nursing, health system, policy, care planning, patient-centered care, medical records, code of ethics.

${ }^{1}$ Department of Nursing, Ashkelon Academic College, ISRAEL. Department of Sociology and Social Work, "Alexandru Ioan Cuza" University of Iasi, ROMANIA. E-mail: beckytsarfati@gmail.com

${ }^{2}$ Department of Sociology and Social Work, "Alexandru Ioan Cuza" University of Iasi, ROMANIA. E-mail: dananacu@gmail.com 


\section{Introduction}

In recent years we have been witnessing a widespread use of computerized technology and digital information by healthcare givers and patients. Although the healthcare system is far behind most industries in the use of technology by healthcare givers, the first and dominant application of technology has been focused on administrative functions. Health Information Technology (HIT) includes Electronic Health Records (EHR) at patients' bedside, smartphones, sensors and monitors for medical documentation and health measurement. Although nurses play a major part in health care, they are the last ones to be involved in and introduced to new information technologies by using Electronic Health Records (EHR). The obligation to maintain privacy has been discussed before the use of EHR. Hence, today, with the introduction of new systems, all health providers as well as system designers and maintainers, are bound by this obligation even more.

The article will present four central ethical issues stemming from the use of electronic records: (1) the built-in conflict between nurses' quality care commitment to health system organization and their commitment to observing patients' respect and privacy; (2) the gap between the one-dimensional reporting of medical and therapeutic information through the technology system that can result in wrong or inappropriate treatment decisions, and the opposite approach according to which health information is collected by a direct nurse-patient communication; (3) the gap between the advantage of the technology system as an easy to operate and use, and the risk of confidential medical information leak that violates patients' privacy. This may result in wrong conclusions by anyone who receives this information and tries - incorrectly - to learn from it with respect of another medical case and, thus, make wrong medical and treatment decisions; (4) the conflict between the nurses' classic professional identity as who takes care and satisfies patients' needs and the new concept of nursing that advocates patient's privacy, autonomy and dignity as part of learning the new technology skill with all its advantages and disadvantages. Going back to paper documentation is inconceivable. The electronic systems with their benefits and shortcomings are going to be our standard of care. We are now obliged to use them in a morally responsible way to keep the nursing code of ethics alive.

\section{Nursing and Nurses' Professional Identity}

As described by the American Nursing Association (ANA, 2019), nursing in the $21^{\text {st }}$ century is a profession consisting of several parallel areas. The heart of the profession places "the patient at the center", followed by fundamental respect for human dignity and an obligation to acknowledge patients' needs. This is backed by the perception structured of precise core learning. The ideology of nursing advocates providing the best possible patient's care through critical reflection, based on integrative knowledge and on application of simple or complicated skills to ensure quality of care (ANA, 2017). Patient-centered care is defined by Newell 
and Jordan (2015) as respectful care for patients' side by side with identifying patients' individual preferences and care givers' responsive acting for them.

The definition of nursing by the International Council of Nurses (ICN) includes the obligation to advocate, promote safe environment, promotion of health, care of the ill, educate, be a part of health policy for individuals of all ages and communities (ICN, 2002). Israel Nursing Administration's definition of nursing includes parts of the ANA and ICN definitions and obligates nurses to give safe, advocating and qualitative care on base of integrative knowledge within human dignity saving (Israel Nursing Administration, 2019).

In the second half of the $20^{\text {th }}$ century, scholars such as Wilensky (1964), argued that professionalization is a product of learning and experience. Its awards individuals the certification and credentials to work in their profession while upholding the rules of professional ethics. Abbott (1981), proposed criteria for distinguishing between a profession and an occupation. Towards the end of the $20^{\text {th }}$ century, researchers such as Benveniste (1987) and Ibarra (1999), changed the perception of professionalism and suggested that professionalism was based on skills or education.

While changing as a society, we have realized that in recent years the attitude towards profession in general and professional identity in particular has been changed also. Today, the definition of professional identity is grounded in the individuals' perception of what it means to be professionals, and to act accordingly. Based on the personal experience as a nurse, maintaining a long-term quality nursing care can be achieved with a strong, yet flexible, professional identity. Nurses' professional identity is affected by their role perception, independence in decision-making, work environment and personal factors. Nurses' professional identity implies being built already during their academic studies as well as continuing their training and exposure to practice. These allow individuals to understand the needs of the profession (Rasmussen, Henderson, Andrew, \& Conroy, 2008).

\section{Social Identity Theory}

According to the social identity theory, individuals develop a social identity through their knowledge about belonging to a social category or group. In the social group, individuals see a similarity to the others in the group concerning beliefs, values, behavioral norms and way of speech. The group members act uniformly in their role (Stets \& Burke, 2000). Nurses are expected to act and think in a similar way as part of the nurses' role definition, based on their academic studies and on the certification granted to them by the relevant authorities. For example, in Israel, nurses' role and the framework of their responsibility are defined by the Nursing Administration, a ministerial body established in 1994 within the Ministry of Health. The objective of this administration is to formulate a policy of nursing as part of the Ministry of Health state lines of action, as well as to develop the nursing profession as an integral part of the health system. Consequently, nurses are expected to provide quality care according to the Nursing Administration rules 
and authorizations. Nurses' professional identity is built of their type of work, special skills and advanced training and can be defined as a social identity because they share a common approach to work (Caza \& Creary, 2016).

\section{Nurses' Code of Ethics}

"The code of ethics is the moral compass that guides the nurses in their work. It is based on a set of ethical and moral values that build society in general and the nursing profession in particular" (Israel Ministry of Health, 2018). In Israel this is the definition of the nursing profession that establishes the obligation of nursing practitioners to maintain and improve the quality of professional practice. The code combines the values of ethics and moral related to patients' rights and caregivers' duties.

American Nurses Association (ANA, 2015) defines the code as a foundation of the nursing theory, expression of values and moral obligations that build nursing as a profession. The code determines the ethical standards and contributes to nursing decision-making process with non-negotiable setting or revision except by ANA (2015). Both the code versions obligate nurses to promote, advocate for and protect the patients' rights of health and safety, by maintaining human dignity, patients' autonomy on their body and autonomy of medical decision-making, informed consent, patients' information confidentiality, as well as an obligation to provide professional qualitive and safe treatment. The use of computerized systems in healthcare, results in a tension between the principles of ANA (Phillips, 2015).

Romania has joined the European Union Nursing Code of Ethics in 2007 (Koff, 2017). The European Code of Ethics is an obligatory document for nurses, designed by the European Federation of Nursing Regulators (Federazoine Europea delle Professioni Infermieristche - FEPI). The purpose of the document is to protect European citizens from malpractice and develop professional standards for first rate quality of health. This document constitutes a framework for nurses who have accomplished their professional recognition and have an obligation to behave based on ethical and moral decision- making. Like ANA and the Israeli code of ethics, FEPI determines that the center of ethical behavior encompasses advocating, protecting, and promoting patients' rights, "Placing the patient first" (Saso et al., 2008). The code has been defined as a set of values and rules, aiming to enhance, support and assess professional practice (Heymans, van der Arend, \& Gastmans, 2007). The code clarifies the profession's values and norms that help building trust relationships between the practitioners and the society which expects nurses to perform in a reliable and high-quality manner (Koff, 2017). Health providers and institutions using EHR must maintain the patients' trust by using electronic records in accordance with privacy and confidentiality regulations. 


\section{Electronic Health Records (EHR)}

There is no doubt that EHR are here to stay as a major part of nursing. The benefits of the systems depend on the nurses' ability to make an effective and efficient use of EHR. The essential result of using EHR is improving patients' safety and enhancing the quality of care by implementing a digital version of the patients' paper chart. Electronic medical systems facilitate patients' data finding, accuracy of documentation and automatic alerts for improving the clinical treatment. Electronic health information is accessible not only in health institutions but can also be found as personal health records and patients' portals. EHR are organized data collection of people or a community, comprising health information about medical history, laboratory test results, personal information, e.g., weight, age, allergies, medications, and more.

Clinical decision support systems (CDSS), as part of EHR, are information systems designed to provide support for clinical decisions made by health caregivers (Sim et al., 2001). Nurses' specific decision-making systems can be found as nursing diagnosis, care planning and symptom management systems, aiming to reduce nursing care errors. Nurses as practitioners who work based on integrative knowledge, can use CDSS to assist in collecting data, summarizing data and linking clinical knowledge within patients' clinical data (Courtney, Alexander, \& Demiris, 2008).

In their article, Despont-Gros, Mueller, and Lovis (2005) define acceptance to use EHR as a users' point of view of those systems. They suggest a five-dimensioned model that includes: users' personality, development procedure, context, and environment in using clinical information systems components, and means for building an acceptance to use EHR. The most human users' characteristics that affect the application of EHR were their experiences with the system and individual attitude towards innovation, based on personal exposure to using the system. New clinical information systems adaptation in nurses' workplace is affected not only by personal characteristics as shown below but also by social and organizational aspects in the workplace. This perception leads to questions like: What is the proper way to expose the nursing team to new systems? When is the most effective time to include new systems? What are the expectations of the organization from the nurses? Technology Acceptance Model (TAM) is a model based on the Theory of Reasoned Action, conceived by Ajzen \& Fishbein (1980). Its objective is to predict and explain the users' intention to use new systems, based on answers to those questions. TAM predicts the individuals" "intention to use" on the basis of two variables" "usefulness of use" as people's belief that using a EHR system would promote their job behavior (Davis, 1989) and "ease of use" as people's belief that using a EHR system would be effortless (Davis, 1989). 


\section{Ethics and Electronic Health Records in an Online World}

The discipline of nursing has been viewed, since Florence Nightingale through all theoreticians until the $21^{\text {st }}$ century, as the profession that built its core around the patients. Patient-centered care is unique in nursing studies and has been reflected in nursing practices, knowledge, and nursing skills. This central focus requires that nursing world organizations develop behavioral and ethical codes to provide the essence of the nursing profession in compliance with a distinctive knowledge base (Ortiz, 2018).

For the last 18 years, the Gallup organization (Milton, 2018), attributed to nurses the highest rank of honesty and ethics. In 2019, 85\% of the Americans indicated that nurses' honesty and ethical standards were "very high" or "high". The concept of trust, honesty and ethical standards have built the core curriculum of nursing studies.

Electronic health records are shared through network systems not only by patients but also by physicians, nurses, insurance personnel, government offices and more. This widespread access to health information makes it necessary to identify ways of maintaining patients' confidentiality and privacy by the users. Electronic records, as opposed to paper-based records, are more transparent, convenient to use, becoming more and easier to steal. Nurses as a major part of patients' care, have unrestricted access to patient's information. Consequently, nurses have a moral and ethical obligation to protect patient's privacy and confidentiality of information (Phillips, 2015). This obligation is underpinned by the nurses' code of ethics, defined by American, European, or Israeli nurses as, the need to protect privacy, autonomy and confidentiality of patients.

\section{Clinical Documentation}

Clinical documentation is sometimes controversial when it relates to privacy, security, and confidentiality requirements, it is even more important, when documents are more accessible as electronic systems. Nurses have a moral responsibility to provide accuracy of medical records. Electronic systems sometimes offer the option of making "copy- paste" from one record to another, even between different patients. Although this nurses' practice of documentation is easier and timesaving, it allows unreliable documentation and can entail legal liability problems. Incorrect records can lead to mistaken treatment decisions and jeopardize patients' safety. Transferring data from one patient to another can also be considered as plagiarism (Philips, 2015).

Being concerned with patients' privacy, the United States and the European Union have developed a framework for mitigating threats to health care information systems. Threats can be created by employees or hackers, natural threats, and technological failures (European Union, 2016; Pear, 2010). 


\section{Nursing Diagnosis and Decision-Making}

Nursing diagnosis consists of interviewing, observing, and examining the patients. When nurses are occupied with documentation on the computer more than with the patients, it makes patients feel a physical barrier. These patients sense as if they have been replaced by the computer and can refuse to share important medical information. This kind of nurse-patient interaction breaks off the core of the nursing profession - "patient-centered care" - as well as breaks off the code of ethics - obligation to provide professional high quality and safe treatment. Diagnosis is a process that requires knowledge of the patients' health data, broad knowledge of health and illnesses, knowledge of human behavior - physical and mental, knowledge of treatments and human values.

The main concern of EHR as a decision support technology is what will happen if the nursing staff that provides health care relies only on decision support system recommendations, without questioning its reliability (Philips, 2015). The care providers moral obligation is to make decisions based on extended knowledge, when the electronical diagnosis systems, combined with the human decisionmaking nurses must have the ability to recognize when the system has made an error. Productive and sufficient use of electronic systems can be achieved by practice, education, and experience. Inadequate preparation can lead to mistaken decision-making (Goodman \& Miller, 2001).

\section{Nurse - Patient Relationship and Communication}

Advocacy and trust constitute the essence of the nursing profession and they are the center of the code of ethics. To maintain nursing practice on those values, health organizations should consider them as high priority values. Patients' well-being must be the main goal, not only for nurses but rather for people who manufacture health information systems (Newell \& Jordan, 2015).

Communication is the simple way of transferring information between two or more people. It is a two-way interactive process that transpires by in verbal or nonverbal, face- to-face or non-face-to-face techniques. Nursing curriculum requires learning communication skills, to provide a high-quality care by diagnosing and learning patients' needs, establishing trust and safe environment for them. The purpose of the patient - centered communication is to create a respectful therapeutic approach, share two-way information, enable patients and family to make clinical decisions together with caring personnel, ask questions and be involved in their own care (Newell \& Jordan, 2015). These actions help maintaining the patients' autonomy on their body, make an informed consent and keep human dignity as part of nursing ethical obligations. Electronic systems can sometimes create a personal and therapeutic distance, which seems to patients as lack of communication. Such situations this can make patients feel uncomfortable to talk, to ask and be involved in making clinical decisions. 


\section{Conclusion}

There is no way we are going back to paper documentation. The electronic systems with their advantages and disadvantages will be our standard of care. We are now obligated to use them in a morally responsible way, keeping nursing code of ethics alive. Ethical considerations are there with the purpose of defining what is right and wrong in the behavior of practitioners.

Privacy is one of the central ethical issues used for people and their wish to keep their health information private, by maintaining the confidentiality of that information. If the newspapers advertise results of individuals' tests, it constitutes a breach of confidentiality. If the newspaper mentions the places which the individuals have visited, this is a violation of their privacy. In electronic health systems the term 'privacy' implies keeping the medical records for the patient's eyes only. Both individuals and society gain when these two values are protected. Patients that feel protected from violation of these values are more communicative, share information more easily and can enjoy a successful nurse-patient relationship. The obligation to maintain privacy has been discussed before the use of EHR. Hence, today, with the introduction of the new systems, all health providers as well as people who design and maintain such systems, must obey this obligation even more. Electronic documentation can lead to plagiarism if nurses make "copy - paste" of data taken from different patients. This issue can be solved if the users are properly trained to use the system. It is providers' responsibility to ensure that in a busy patients' schedule, nurses will practice with the electronic systems (Philips, 2015).

Ethical professional obligations to patients set professional challenges in lots of nursing patient-care areas, such as clinical documentation, nursing diagnosis and decision-making, nurse-patient relationship and communication, information, and advice in the social media. Nursing in the technological age poses major challenges to nurses' professional-social identity, by making nurses' practice with computers rather than engage in professional interaction.

Health care systems have expanded and changed over the years, requiring nurses to make a role change due to the impact of new technologies and increased health care expectations. The $21^{\text {th }}$ century requires nurses to develop new clinical thinking and implementation skills, to be more flexible and adaptive to changes and innovations (Rasmussen et al., 2008). Nurses embrace the changes while understanding new ethical issues, by using new technologies when patient's safety and outcomes are at stake.

For the nurses that shapes the next generation of nurses, we suggest that including further learning of computer skills and the use of EHR, may be the beginning of involving nursing students in health system demands. It can facilitate the nurses' adaptation to the use of EHR, while at the same time maintaining the code of ethics. 


\section{References}

Abbott, A. (1981). Status and status strain in the professions. American Journal of Sociology, 86, 819-835.

Ajzen, I., \& Fishbein, M. (1980). Understanding attitudes and predicting social behavior. Englewood Cliffs, NJ: Prentice-Hall.

American Nurses Association (2014). Nurses'code of ethics. Silver Spring, MD: American Nurses Association.

American Nurses Association (ANA) - ANA Enterprise. (2017). Retrieved from https:// www.nursingworld.org.

Benveniste, G. (1987). Professionalizing the Organization: Reducing Bureaucracy to Enhance Effectiveness. San Francisco, CA: Jossey-Bass.

Caza, B.B., \& Creary, S.J. (2016). The construction of professional identity [Electronic version]. Retrieved [12.2019] fromL Cornell University, SHA School site: http:// scholarship.sha.cornell.edu/articles/878

Courtney, K. L., Alexander, G. L., \& Demiris, G. (2008). Information technology from novice to expert: implementation implications. Journal of Nursing Management. 16(6): 692-699. DOI:10.1111/j.1365-2834.2007. 00829.x

Davis, F.D. (1989). Perceived usefulness, perceived ease of use, and user acceptance of information technology. MIS Quarterly, 13(3), 319-340. DOI: 10.23-7/JSTOR.

Despont-Gros, C., Mueller, H., \& Lovis, C. (2005). Evaluating user interactions with clinical information systems: a model based on human-computer interaction models. Journal of Biomedical Informatics, 38(3), 244-255. DOI:10.1016/jbi.2004.12.004

European Union (2016). General Data Protection Regulation - GDPR.2016/ 679.

Goodman, K. W., \& Miller, R.A. (2001). Ethics and Health Informatics: Users, Standards and Outcomes. Medical Informatics, 257-281.

Heymans, R., van der Arend, A., \& Gastmans, G. (2007). Dutch Nurses' views on Codes of Ethics. Nursing Ethics, 14(2), 70-156, DOI: 10.1177/0969733007073696.

Ibarra, H. (1999). Provisional selves: Experimenting with image and identity in professional adaptation. Administrative Science Quarterly, 44(4), 764-791.

International Council of Nurses (ICN) (2002). Nursing definitions. retrieved from https:// www.inc.ch/nursing policy/ nursing definitions.

Israel Ministry of Health (2018). The Ethical Code of Nurses. Retrieved from: https:// www.health.gov.il

Israel Nursing Administration (2019). Retrieved from: https://www.health. gov.il/ UnitsOffice/nursing/nursingStudies/Pages/programs.aspx

Koff, S.Z. (2017). Nursing in the European Union: Anatomy of a Profession, volume 1, New York, USA: Routledge.

Milton, C.L. (2018). Will Nursing Continue as the Most Trusted Profession? An Ethical Overview. Nursing Science Quarterly, 31(1), 15-16. DOI: $10.1177 / 0894318417741099$.

Newell, S., \& Jordan, Z. (2015). The Patient Experience of Patient-Centered Communication with Nurses in the Hospital Setting: A Qualitative Systematic Review Protocol. JBI Evidence Synthesis, 13(1), 76-87. DOI: 10.11124/jbisrir-2015-1072.

Ortiz, M.R. (2018). Patient-Centered care: Nursing Knowledge and Policy. Nursing Science Quarterly. Sage Journals, 31(3), 291-295. DOI: 10.1177/0894318418774906

Pear, R. (2010). Standards Issued for Electronic Records. The New- York Times. 
Phillips, W. (2015). Ethical Controversies about Proper Health Informatics Practices. Science of Medicine - Health Management and Informatics ,112(1), 53-57.

Rasmussen, P., Henderson, A., Andrew, N., \& Conroy, T. (2008). Factors Influencing Registered Nurses' Perceptions of Their Professional Identity: An Integrative Literature Review. The Journal of Continuing Education in Nursing; Thoroughfare, 49(5), 225-232.DOI: 10.3928/00220124-20180417-08.

Saso, L., Stievano, A., Jurado, M., G., Rocco, G., (2008), Code of Ethics and Conduct for European Nursing. Nursing Ethics ,15:821. DOI: 10.1177/0969733008095390.

Sim, I., Gorman, P., Greenes, R. A, Hayness, B., Kaplan, B., Lehmann, H., \& Tang, P. C. (2001). Clinical decision support systems for the practice of evidence-based medicine. Journal of the American Medical Informatics Association. 8(6), 527-534. DOI: 10.1136/jamia.2001.0080527

Stets, J E.,\& Burke, P.J. (2000). Identity Theory and Social Identity Theory. Social Psychology Quarterly, 63(3), 224-237.

Wilensky, H. (1964). The professionalization of everyone? American Journal of Sociology, 70, 37-158. 